\title{
Reducing fuzziness in abrasive sanding of rubberwood (Hevea brasiliensis)
}

\begin{abstract}
Rubberwood (Hevea brasiliensis) is the predominant wood raw material for the furniture industry in South East Asia. However, the prevalence of surface fuzziness after the abrasive sanding process contributes towards the low processing yield. In an effort to reduce the manifestation of surface fuzziness, a series of experiments was carried out in the laboratory using a cross-head wide-belt sander. The results showed that the sanding grit 120 on the cross-head, followed by sanding grits 150 and 180 produced the best surface quality.
\end{abstract}

Keyword: fuzziness, rubberwood, Hevea brasiliensis 